\title{
Large Cell Neuroendocrine Carcinoma
}

National Cancer Institute

\section{Source}

National Cancer Institute. Large Cell Neuroendocrine Carcinoma. NCI Thesaurus. Code C6875.

A usually aggressive carcinoma composed of large malignant cells which display neuroendocrine characteristics. It is characterized by the presence of high mitotic activity and necrotic changes. The vast majority of cases are positive for neuron-specific enolase. Representative examples include lung, breast, cervical, and thymic neuroendocrine carcinomas. 